\title{
Countermeasures for avian influenza outbreaks among captive avian collections at zoological gardens and aquariums in Japan
}

\begin{abstract}
Japan is situated along the East Asian Flyway, which is an important migratory route. Outbreaks of infectious disease could impact bird populations along this route, and is expected to have a negative influence on captive bird populations. Here, we provide a brief overview of the situation regarding avian influenza (AI) in both free-ranging and captive avian species in Japan. We also suggest suitable countermeasures for the prevention and management of AI outbreaks in zoological gardens and aquariums, with special reference to the control of free-ranging duck populations and/or individuals and the nationwide surveillance of AI viruses. Furthermore, we have disclosed the prominence of vaccination program for zoological collections in Japan.
\end{abstract}

Keywords: avian influenza, vaccination, zoological collection in Japan
Volume 7 Issue 3 - 2019

\author{
Masayoshi Kakogawa, ${ }^{1,2}$ Manabu Onuma, ${ }^{2,3}$ \\ Rikio Kirisawa, ${ }^{2}$ Mitsuhiko Asakawa ${ }^{2}$ \\ 'Kobe Animal Kingdom, Japan \\ ${ }^{2}$ Graduate School of Veterinary Medicine, Rakuno Gakuen \\ University, Japan \\ ${ }^{3}$ Center for Environmental Biology and Ecosystems studies, \\ National Institute for Environmental Studies, Japan
}

\begin{abstract}
Correspondence: Mitsuhiko Asakawa, Graduate School of Veterinary Medicine, Rakuno Gakuen University, Ebetsu, Hokkaido 069-850I, Japan, Email askam@rakuno.ac.jp
\end{abstract}

Received: June 06, 2019 | Published: June 21, 2019

\section{Background}

Despite considerable environmental changes over the last 160 years, ${ }^{1,2}$ Japan is an important transit country for a wide range of migratory avian species. It is situated on the East Asian Flyway, a principal migratory route connecting Northeast Asia with Southeast Asia. Major branches pass through the Nansei-Shoto Islands, Kyushu, Honshu, and Hokkaido into northeast Russia, and via Kyushu and the Korean Peninsula into eastern China. ${ }^{3}$ So far, Japan has escaped the outbreaks of infectious disease that have significantly impacted bird populations in other parts of the world. ${ }^{1,2,4}$ During these outbreaks, tens of thousands of birds become sick leading to death in extreme cases. ${ }^{5}$ In addition to the changing avian fauna and ecosystems in Japan, a large number of captive birds are kept in over 150 zoological gardens and/or aquariums throughout the country (http://www.jaza. jp/z_map/z_seek00.html). It is therefore likely that these captive birds would also be affected if a disease outbreak occurs.

Although there are numerous infectious diseases that affect both free-ranging and captive avian species, this review contains a brief overview of the situation regarding avian influenza (AI) in Japan, as well as suggestions for the implementation of countermeasures for the prevention and management of potential AI outbreaks. First described in the late 19th century, AI is a highly contagious viral disease affecting birds, especially poultry, worldwide. AI viruses are generally isolated from wild birds, particularly migratory waterfowl belonging to the orders Anseriformes and Charadriiformes, which are considered natural reservoirs of the viruses. ${ }^{5}$ However, since 2004, highly pathogenic (HP) AI has been classified as a typical and re-emerging infectious disease of avian species by the Japanese government and the science community responsible for animal health. ${ }^{1-4}$ Therefore, the current review provides an overview of recent changes in AI and its causative agents in both free-ranging and captive avian species worldwide, including Japan, and provides potential strategies to manage epidemic risk in facilities with captive birds or zoological collections.

\section{General characteristics of $\mathrm{Al}$ and its causative agents}

AI is caused by influenza type A viruses, consisting of negativesense, single-stranded RNA viruses belonging to the family Orthomyxoviridae. Influenza A virus genomes contain eight segments encoding 11 proteins. Segments one to six encode PB2, PB1, PB1-F2, PA, hemagglutinin (HA), nucleoprotein NP, and neuraminidase (NA) in decreasing order in size. The seventh and eighth segments encode M1, M2, NS1, and NS2. The viruses are further categorized into various subtypes based on the combination of $\mathrm{HA}(\mathrm{H} 1-\mathrm{H} 16)$ and NA (N1-N9) antigens. Various influenza A virus subtypes occur in wild birds, especially aquatic species, and may also infect mammals such as humans and pigs. ${ }^{1,3,6}$

AI viruses are globally distributed and are probably prevalent in area with higher host population. ${ }^{3} \mathrm{AI}$ or its causative viruses have been reported in over 100 free-ranging bird species belonging to 13 avian orders. ${ }^{3,6}$ Among these, birds belonging to the orders Anseriformes, including dabbling ducks, diving ducks, geese, and swans, and the order Charadriiformes, including gulls, terns, and shorebirds, serve as vital viral reservoirs. ${ }^{6}$ However, most reports of AI have been in birds from the family Anatidae (Anseriformes), with AI viruses having been isolated from over 30 duck and goose species worldwide. ${ }^{6}$

The pathogenicity of AI viruses varies significantly according to the subtype. The pathogenicity depends on several factors which are as follows: i) The outcome of intravenous pathogenic index assays in chickens, ii) The amino acid sequence at the hemagglutinin cleavage site, or iii) The ability of the virus to cause cytopathic effects in cell culture in the absence of trypsin. To date, highly pathogenic strains have been restricted to the $\mathrm{H} 5$ and $\mathrm{H} 7$ subtypes, although most $\mathrm{H} 5$ and $\mathrm{H} 7$ viruses display low pathogenic properties. Cleavage of the hemagglutinin protein is of paramount importance in determining virulence, but the combination of genes, including the nucleoprotein and polymerase genes cannot be denied. The HPAI viruses contain alterations in their cleavage sites that allow the precursor hemagglutinin to be processed by a variety of ubiquitous intracellular 
proteases found in many body tissues, resulting in the potential for systemic, multi-organ infections. ${ }^{7-9}$

\section{Recent outbreaks of HPAI}

Since 2017, outbreaks of HPAI in poultry have occurred in 19 countries in Asia, two countries in North America, 28 countries in Europe, seven countries in Africa, and in Russia and Serbia (Table 1). ${ }^{10}$ As a result of several HPAI outbreaks in Japan since 2004, the Ministry of Agriculture, Forestry, and Fisheries (MAFF) carried out an annual review of all outbreaks (Table 2). The most common pathogenic HPAI virus subtypes are H5N1, H5N6, and H7N7. However, there are slight differences in the predominant subtypes for each continent. For example, subtype $\mathrm{H} 5 \mathrm{~N} 1$ is frequently found in Asian countries, while subtype H5N8 is more common in Europe. In comparison, $\mathrm{H} 5 \mathrm{~N} 1$ and $\mathrm{H} 5 \mathrm{~N} 8$ are the predominant subtypes in most African countries. Differences in the frequency of the various subtypes among countries and/or continents appear to be associated with proximity to the different migratory bird flyways. The major migratory routes include the East Asian/Australasian, the Central Asian, and the Black Sea/Mediterranean flyways. ${ }^{11,12}$ Because all three flyways share common northern destinations, for the probability of AI viruses to spread from locations in Siberia and Alaska to other parts of the world, including Japan is higher. ${ }^{13}$

Table I Subtypes responsible for recent outbreaks of the HPAI in the world since 2017

\begin{tabular}{|c|c|c|c|c|c|}
\hline \multirow{2}{*}{$\begin{array}{l}\text { Country } \\
\text { Asia }\end{array}$} & \multirow[b]{2}{*}{ Japan } & \multicolumn{2}{|c|}{ Subtype of HPAI } & \multirow[b]{4}{*}{ H5N8 } & \multirow[b]{4}{*}{ H7N9 } \\
\hline & & H5N6 & & & \\
\hline & Korea & H5N6 & H5N8 & & \\
\hline & China & $\mathrm{H} 5 \mathrm{NI}$ & H5N6 & & \\
\hline & Taiwan & $\mathrm{H} 5 \mathrm{~N} 2$ & H5N6 & H5N8 & \\
\hline & Hong Kong & H5N6 & & & \\
\hline & Malaysia & $\mathrm{H} 5 \mathrm{NI}$ & & & \\
\hline & Vietnam & $\mathrm{H} 5 \mathrm{NI}$ & H5N6 & & \\
\hline & Laos & $\mathrm{H} 5 \mathrm{NI}$ & & & \\
\hline & Philippines & H5N6 & & & \\
\hline & Cambodia & $\mathrm{H} 5 \mathrm{NI}$ & H5N6 & & \\
\hline & Myanmar & $\mathrm{H} 5 *$ & H5N1 & & \\
\hline & Nepal & $\mathrm{H} 5 \mathrm{NI}$ & H5N8 & & \\
\hline & Indonesia & $\mathrm{H} 5 \mathrm{NI}$ & & & \\
\hline & India & $\mathrm{H} 5 \mathrm{NI}$ & H5N8 & & \\
\hline & Bangladesh & $\mathrm{H} 5^{*}$ & H5N1 & & \\
\hline & Iran & $\mathrm{H} 5 \mathrm{NI}$ & H5N8 & & \\
\hline & Bhutan & $\mathrm{H} 5 \mathrm{NI}$ & & & \\
\hline & Iraq & H5N8 & & & \\
\hline & Israel & H5N8 & & & \\
\hline \multirow{2}{*}{$\begin{array}{l}\text { North } \\
\text { America }\end{array}$} & America & $\mathrm{H} 5^{*}$ & & & \\
\hline & Mexico & H7N3 & & & \\
\hline Europe & Italy & H5N8 & & & \\
\hline
\end{tabular}

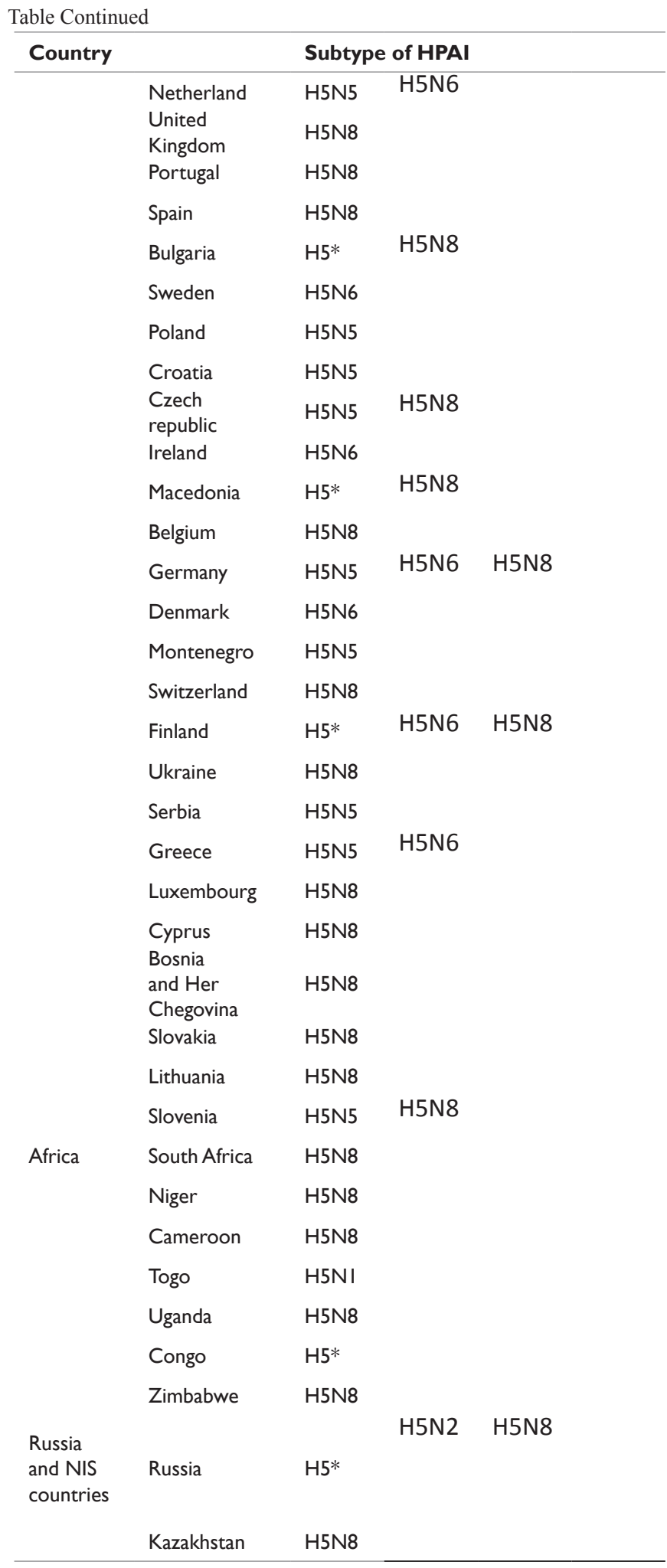

*: Subtype of the Al viruses is unknown.

HPAI infections, most of which were caused subtype H5N8 viruses, were recorded in 33 zoological gardens across 15 countries in Europe and Asia between October 2016 and March 2017. ${ }^{14}$ In 
Asia, most of these infections occurred in local water fowl species in India, including rosy pelican (Pelecanus onocrotalus), barheaded goose (Anser indicus), greylag goose (Anser anser), and painted stork (Mycteria leucocephala), housed at Gwailor Zoo, the National Zoological Park, Tata Zoo, Mysore Zoo, and Nandankanann Zoological Park. ${ }^{15}$ In Europe, however, the HPAI infections occurred in various bird species from zoological collections in several different countries, including emu (Dromaius novaehollandiae) at Ueckermünde Zoo in Germany, swans at Liberec Zoo in the Czech Republic, and a Dalmatian pelican (Pelecanus crispus) at Schönbrunn Zoo in Austria. Within the zoological collections, the HPAI outbreaks were not restricted to avian species, with tigers (Panthera tigiris), leopards (Panthera pardus), and lions (Panthera leo) also affected in Thailand and China. The feeding of infected chickens to these large carnivores was the reason for the onset of the disease. ${ }^{16-19}$ On both continents, the possibility of infection being contracted from wild birds was considered likely.
Several fatal or severe cases of HPAI infection (subtypes H5N1 or H5N6) have been recorded in Japanese zoological collections between 2010 and 2016. These included a mute swan (Cygnus olor) at Takaoka Kojo Park in Toyama, three black swans (C. atratus) and three snowy owls (Bubo scandiacus) at Omoriyama Zoo in Akita Prefecture, and three black swans, four cackling geese (Branta hutchinsii), two mallard ducks (Anas platyrhynchos), and a Eurasian wigeon (Anas penelope) at Higashiyama Zoo in Aichi Prefecture..$^{20-25}$

In comparison, there have been very few reported cases of HPAI infection in free-ranging birds in Japan, with only three whooper swans (Cygnus cygnus) affected between 2007 and 2009. ${ }^{2}$ However, after the introduction of a nationwide surveillance program for detection of AI virus in birds, a total of 60 individuals belonging to 15 wild birds species, including both migratory and resident species, were found to have contracted HPAI virus infections between 2010 and 2011 (Table 2). ${ }^{4}$

Table2 Recent outbreaks of the HPAI in Japanese birds between 2005 and 2018

\begin{tabular}{|c|c|c|c|c|c|c|c|c|c|c|c|c|c|}
\hline & $\begin{array}{l}2005- \\
2006\end{array}$ & $\begin{array}{l}2006- \\
2007\end{array}$ & $\begin{array}{l}2007- \\
2008\end{array}$ & $\begin{array}{l}2008- \\
2009\end{array}$ & $\begin{array}{l}2009- \\
2010\end{array}$ & $\begin{array}{l}2010- \\
2011\end{array}$ & $\begin{array}{l}2011- \\
2012\end{array}$ & $\begin{array}{l}2012- \\
2013\end{array}$ & $\begin{array}{l}2013- \\
2014\end{array}$ & $\begin{array}{l}2014- \\
2015\end{array}$ & $\begin{array}{l}2015- \\
2016\end{array}$ & $\begin{array}{l}2016- \\
2017\end{array}$ & $2017-2018$ \\
\hline Poulty & $4 I(9 *)$ & 4 & 0 & 7 & 0 & 24 & 23 & 0 & 0 & 5 & 0 & 12 & 1 \\
\hline $\begin{array}{l}\text { Free- } \\
\text { ranging }\end{array}$ & 0 & 0 & 3 & 0 & 0 & 60 & 0 & 0 & 0 & $13 * *$ & 0 & 200 & 46 \\
\hline TOTAL & $4 I(9 *)$ & 4 & 3 & 7 & 0 & 84 & 23 & 0 & 0 & 18 & 0 & 212 & 47 \\
\hline
\end{tabular}

*: Number of antibody-positive cases.

**: Number of positive cases partly derived from the materials of feces and environmental samples (eg., water, soil etc).

\section{Nationwide surveillance of $\mathrm{Al}$ viruses in Japan}

Because of the role of free-ranging birds in AI virus epidemics in Japan, a nationwide surveillance program to detect the viruses in fecal or blood samples from wild birds was introduced by the Ministry of Environment in $2008 .^{38}$ According to the survey results, including unpublished data, the general AI virus prevalence ranged from $1.4 \%$ $2.2 \%$ in the 10-year period between 2008 and 2018. The highest prevalence rates were recorded between October and December each year, just after the autumn migration. Onuma et al., ${ }^{3}$ showed that three routes were likely responsible for the introduction of the AI viruses to Japan, with the direct crossing of the Sea of Japan and entry through the Korean Peninsula identified as the two main routes. In addition, the study showed that the so-called mallards-eastern spot-billed duck group (Anas platyrhynchos and/or Anas zonorhyncha) and Northern pintails (Anas acuta) were the species most likely to have carried the AI viruses into Japan.

However, as mentioned above, the viruses have also been isolated from species belonging to the order Charadriiformes. ${ }^{5}$ Thus, an investigation into the prevalence of AI viruses in Charadriiformes shorebirds from Hokkaido, the stopover site along the flyway, was performed. ${ }^{26}$ Blood samples were collected from 1749 individual birds; however, AI virus was only detected in one individual identified as a lesser sand plover (Charadrius mongolus), corresponding to an overall prevalence of $0.06 \%$. Hence, shorebirds are unlikely to be vehicles of AI virus transmission in Japan. ${ }^{26}$

\section{Countermeasures for management of Al virus infection in zoological collections in Japan}

As per the Domestic Animal Infectious Disease Control Law of Japan, if an AI outbreak occurs in poultry such as chickens or ducks, the affected facilities come under the control of regional livestock hygiene service centers. In comparison, in the case of infections in other birds, including wild birds and those housed in zoological collections, the Technical Manual for Highly Pathogenic Avian Influenza in Wild Birds (translated title) ${ }^{8}$ is applied as a general countermeasure against infection. In addition, for zoos and aquariums, the Guidelines of Countermeasures for Highly Pathogenic Avian Influenza Infection for Captive Breeding Birds (translated title) ${ }^{27}$ should be referenced. The Guidelines suggest that each step of the countermeasures should be followed for the three outbreak situation levels. These levels are: level 1, outbreak has not yet occurred; level 2, poultry outbreak; level 3, outbreak in a zoological collection. Unfortunately, there is no clear guideline on whether to preserve by treatment or to euthanize birds from zoos and aquariums in the event of AI virus infection in birds included on the International Union for Conservation of Nature Red List of Threatened Species or mentioned in the Convention on International Trade in Endangered Species. Hence, clear guidelines should be published in the near future.

Furthermore, we recommend that the Japanese government should consider implementing an AI vaccination program for endangered avian species, such as that recommended by the World Organisation for Animal Health (OIE). ${ }^{28-33}$ According to the Manual of Diagnostic 
Tests and Vaccines for Terrestrial Animals published by the OIE, most North American and European zoos adopt the program using the water-in-oil adjuvanted $\mathrm{H} 5 \mathrm{~N} 2$ vaccine (Nobilis $\left.{ }^{\circledR}\right)$ or $\mathrm{H} 5 \mathrm{~N} 9$ vaccine (Poulvac $($ ). Captive birds were vaccinated twice via subcutaneous or intramuscular injection with a 3-6 week interval. In general, a "high" or "good" titer was obtained in $>60 \%$ of vaccinated birds. ${ }^{34-39}$ However, a similar vaccination program has been not permitted in Japan. $^{40-57}$

\section{Conclusion}

In conclusion, there are several suitable countermeasures for the prevention and management of AI outbreaks in zoological gardens and aquariums in Japan. Based on the systematic and nationwide surveys conducted in Japan since 2008, the prevalence of AI virus appears to be highest during the autumn migration period. In addition, mallard ducks, eastern spot-billed ducks, and northern pintails play an important role in introducing AI virus into Japan. Hence, zoos and aquariums should attempt to prevent duck species, especially the three species mentioned above, from gaining access to their facilities during the autumn migration period. Further, depending on population numbers, a cull of these duck species may need to be carried out at affected facilities. Because there are also resident populations of mallard and eastern spot-billed ducks in Japan, it would be preferable to prevent these species from entering zoos and aquariums at any time, especially during the autumn migration and wintering periods. Finally, in addition to general sanitary and quarantine procedures mentioned above, an AI virus vaccination program is needed in Japan.

\section{Acknowledgments}

This study was supported partly by the Environment Reserch and Technology Development Fund (S II-1) of the Environmental Restoration and Conservation Agency of Japan, by the Strategic Research Foundation at Private Universities (2013-2017), and by a Grant-in-Aid for Scientific Research (C-23570120 and C-26460513) from the Ministry of Education, Culture, Sports, Science and Technology of Japan, respectively. We would like to thank Tamsin Sheen, PhD, of the Edanz Group (www.edanzediting.com/ac), for editing a draft of this manuscript.

\section{Conflicts of interest}

Authors declare that there is no conflict of interest.

\section{References}

1. Asakawa M, Nakade T, Murata S, et al. Recent viral diseases of Japanese anatid with a fatal case of Marek's disease in an endangered species, whitefronted goose (Anser albifrons). In: Hambrick J \& Gammon LT (eds) Ducks: Habitat, Behavior and Diseases. Nova Science Publishers Inc. USA; 2013. 37-48 p.

2. Asakawa M, Nakamura S, Brazil MA. An overview of infectious and parasitic diseases in relation to the conservation biology of the Japanese avifauna. Journal of Yamashina Institute for Ornithology. 2002;34(1):200-221.

3. Onuma M, Kakogawa M, Yanagisawa M, et al. Characterizing the temporal patterns of avian influenza virus introduction into Japan by migratory birds. $J$ Vet Med Sci. 2017;79(5):943-951.

4. Hirayama T, Ushiyama K, Osa $\mathrm{Y}$ et al. Recent infectious diseases or theirresponsible agents recorded from Japanese wild birds. In: Ruiz L \& Iglesias F (eds) Birds: Evolution, Behavior, Breeding Strategies, Migration and Spread of Disease. Nova Science: USA; 2013. 83-95 p.
5. Friend M \& Franson JC. Field Manual of Wildlife Diseases. In: Genaral Field Procedures and Diseases of Birds. Geological Survey Madison Wildlife Biological Resources Division: USA; 1999.

6. Stallknecht DE, Nagy E, Hunter DB, et al. Avian influenza. In: Thomas NJ, Hunter DB \& Atkinson CT (eds) Infectious Disease of Wild Birds. Blackwell Publishing: Oxford; 2007. 108-130 p.

7. Desvaux S, Marx N, Ong S, et al. Highly pathogenic avian influenza virus (H5N1) outbreak in captive wild birds and cats, Cambodia. Emerg Infect Dis. 2009;15(3):475-478.

8. Correspondence technical manual pertaining to highly pathogenic avian influenza in the wild bird (in Japanese). MOE; 2017. 157 p.

9. Avian influenza (infection with avian influenza viruses). Chapter 3.3.4. In: Manual of Diagnostic Tests and Vaccines for Terrestrial Animals 2018. OIE (World Organization for Animal Health); 2015. 821-843 p.

10. The world outbreaks of avian influenza in poultry since (in Japanese). MAFF (Ministry of Agriculture, Forestry and Fisheries, Japan); 2019.

11. Tian H, Zhou S, Dong L, et al. Avian influenza H5N1 viral and migration networks in Asia. Proc Natl Acad Sci U S A. 2015;112(1):172-177.

12. Verhagen JH, van der Jeugd HP, Nolet BA, et al. Wild bird surveillance around outbreaks of highly pathogenic avian influenza A (H5N8) virus in the Netherlands, 2014, within the context of global flyways. Euro Surveill. 2015;20(12):21-32.

13. Takemae N, Tsunekuni R, Sharshov K, et al. Five distinct reassortants of H5N6 highly pathogenic avian influenza A viruses a $\square$ ected Japan during the winter of 2016-2017. Virology. 2017;512:8-20.

14. Highly pathogenic H5 avian influenza in 2016 and 2017. FAO (Food and Agriculture Organization of the United Nations); 2017. 16 p.

15. Nagarajan S, Kumar M, Murugkar HV, et al. Novel reassortant highly pathogenic avian influenza (H5N8) virus in zoos, India. Emerg Infect Dis. 2017;23(4):717-719.

16. Chen W, Calvo PA, Malide D, et al. A novel influenza A virus mitochondrial protein that induces cell death. Nat Med. 2001;7(12):1306-1312.

17. Hu T, Zhao H, Zhang Y, et al. Fatal influenza A (H5N1) virus infection in zoo-housed tigers in Yunnan Province, China. Scientific Reports-Nature. 2016;6:25845.

18. Keawcharoen J, Oraveerakul K, Kuiken T, et al. Avian influenza H5N1 in tigers and leopards. Emerg Infect Dis. 2004;10(12):2189-2191.

19. Thanawongnuwech R, Amonsin A, Tantilertcharoen R, et al. Probable tiger-to-tiger transmission of avian influenza H5N1. Emerg Infect Dis. 2005;11(5):699-701.

20. HPAI in Omoriyama Zoo (in Japanese). Akita Prefecture; 2016.

21. Nagoya-shi. HPAI in Higashiyama zoo (First report) (in Japanese); 2016.

22. Nagoya-shi. HPAI in Higashiyama zoo (Second report) (in Japanese); 2016.

23. Nagoya-shi. HPAI in Higashiyama zoo (Third report) (in Japanese); 2016.

24. Nagoya-shi. HPAI in Higashiyama zoo (Fourth report) (in Japanese); 2016.

25. HPAI in Takaoka Kojo Park (in Japanese). Toyama Prefecture; 2011.

26. Kakogawa M, Onuma M, Saito K, et al. Epidemiological survey of avian influenza virus infection in shorebirds captured in Hokkaido, Japan. Journal of Wildlife Diseases. In submission.

27. Correspondence guidelines for highly pathogenic avian influenza of breeding birds in zoos (in Japanese). MOE (Ministry of Environment, Japan); 2017. 8 p. 
28. Avian influenza: Guidelines for prevention in North American zoos. Animal Health Committee of American Zoo and Aquarium Association; 2005. 5 p

29. Transmissible diseases handbook $\square$. Avian influenza. EAZWV; 2007. 15 p.

30. Leong HK, Goh CS, Chew ST, et al. Prevention and control of avian influenza in Singapore. Ann Acad Med Singapore. 2008;37(6):504-509.

31. Avian influenza vaccination. OIE; 2007. 12 p.

32. Concept of Operations Plan: Management of an Avian Influenza Outbreak at a Zoological Institution. USDA Animal and Plant Health Inspection Service; 2015.24 p.

33. Management Guidelines for Avian Influenza: Zoological Parks and Exhibitors Outbreak Management Plan. USDA, APHIS and AZA; 2009. $43 \mathrm{p}$.

34. Alert VJ, Bellon FH, Busquets $\mathrm{N}$, et al. Comprehensive serological analysis of two successive heterologous vaccines against $\mathrm{H} 5 \mathrm{~N} 1$ avian influenza virus in exotic birds in zoos. Clinical and Vaccine Immunology. 2011;18(5):697-706.

35. Bertelsen MF, Klausen J, Holm E, et al. Serological response to vaccination against avian influenza in zoo-birds using an inactivated H5N9 vaccine. Vaccine. 2007;25(22):4345-4349.

36. Dolka B, Żbikowski A, Dolka I, et al. The response of mute swans (Cygnus olor, Gm. 1789) to vaccination against avian influenza with an inactivated H5N2 vaccine. Acta Vet Scand. 2016;58(1):74

37. Lécu A, Langhe DC, Petit T, et al. Serologic response and safety to vaccination against avian influenza using inactivated $\mathrm{H} 5 \mathrm{~N} 2$ vaccine in zoo birds. J Zoo Wildl Med. 2009;40(4):731-743.

38. Philippa JDW, Baas C, Beyer W, et al. Vaccination against highly pathogenic avian influenza $\mathrm{H} 5 \mathrm{~N} 1$ virus in zoos using an adjuvanted inactivated H5N2 vaccine. Vaccine. 2007;25(19):3800-3808.

39. Philippa JDW, Munster VJ, Bolhuis H, et al. Highly pathogenic avian influenza (H7N7): Vaccination of zoo birds and transmission to nonpoultry species. Vaccine. 2005;23(50):5743-5750.

40. Amonsin A, Payungporn S, Theamboonlers A, et al. Genetic characterization of $\mathrm{H} 5 \mathrm{~N} 1$ influenza A viruses isolated from zoo tigers in Thailand. Virology. 2006;344(2):480-491.

41. Alexander DJ. A review of avian influenza in different bird species. Vet Microbiol. 2000;74(1-2):3-13.

42. Chen Q, Wang H, Zhao L, et al. First documented case of avian influenza (H5N1) virus infection in a lion. Emerg Microbes Infect. 2016;5(12):e125-127.

43. Clerc MG, Lebarbenchon C, Thomas F. Recent expansion of highly pathogenic avian influenza H5N1: a critical review. Ibis. 2007;149(2):202-214.
44. Ellis TM, Bousfield R, Bisset L, et al. Investigation of outbreaks of highly pathogenic $\mathrm{H} 5 \mathrm{~N} 1$ avian influenza in waterfowl and wild birds in Hong Kong in late 2002. Avian Pathol. 2004;33(5):492-505.

45. Fouchier RA, Munster V, Wallensten A, et al. Characterization of a nove influenza A virus hemagglutinin subtype (H16) obtained from blackheaded gulls. J Virol. 2005;79(5):2814-2822.

46. Globig A, Starick E, Homeier T, et al. Epidemiological and molecular analysis of an outbreak of highly pathogenic avian influenza H5N8 clade 2. 3. 4. 4 in German zoo: Effective disease control with minimal culling. Transbound Emerg Dis. 2016;64(6):1813-1824.

47. Infectious disease Handbook of Zoo and Aquarium animals: Highly pathogenic avian influenza (in Japanese). JAZA (Japanese Association of Zoos and Aquariums); 2006. 6 p.

48. Olsen B, Munster VJ, Wallensten A, et al. Global patterns of influenza a virus in wild birds. Science. 2006;312(5772):384-388.

49. Check-List of Japanese Birds. 7th ed. Ornithological Society of Japan: Tokyo; 2012

50. Quirk M. Zoo tigers succumb to avian influenza. Lancet Infect Dis. 2004;4(12):716.

51. Röhm C, Zhou N, Süss J, et al. Characterization of a novel influenza hemagglutinin, H15: criteria for determination of influenza A subtypes. Virology. 1996;217(2):508-516.

52. Shivakoti S, Ito H, Otsuki K, et al. Characterization of H5N1 highly pathogenic avian influenza virus isolated from a mountain hawk eagle in Japan. J Vet Med Sci. 2010;72(4):459-463.

53. Vaccination programme for birds kept in zoos against avian influenza submitted by Sweden for approval by the commission Rev. 1. Sweden; 2006. 9 p.

54. Wang G, Zhan D, Li L, et al. H5N1 avian influenza re-emergence of Lake Qinghai: phylogenetic and antigenic analyses of the newly isolated viruses and roles of migratory birds in virus circulation. J Gen Virol. 2008;89(Pt3):697-702.

55. Webster RG, Bean WJ, Gorman OT, et al. Evolution and ecology of influenza A viruses. Microbiol Rev. 1992;56(1):152-179.

56. Yoon SW, Webby RJ, Webster RG. Evolution and ecology of influenza A viruses. Curr Top Microbiol Immunol. 2014;385: 359-375.

57. Yoshida H, Sakoda Y, Endo M, et al. Evaluation of the reverse transcription loop-mediated isothermal amplification (RT-LAMP) as a screening method for the detection of influenza viruses in the fecal materials of water birds. $J$ Vet Med Sci. 2011;73(6):753-758. 